\title{
BMJ
}

\section{Cost effectiveness of COX 2 selective inhibitors and traditional NSAIDs alone or in combination with a proton pump inhibitor for people with osteoarthritis}

\author{
Nicholas Latimer, research fellow in health economics, ${ }^{1}$ Joanne Lord, reader in health economics, ${ }^{2}$ \\ Robert L Grant, senior technical adviser, ${ }^{3}$ medical statistician, ${ }^{4}$ Rachel O'Mahony, research fellow, ${ }^{3}$ \\ John Dickson, community physician in rheumatology, ${ }^{5}$ Philip G Conaghan, professor of musculoskeletal \\ medicine ${ }^{6}$ on behalf of the National Institute for Health and Clinical Excellence Osteoarthritis Guideline \\ Development Group
}

\begin{abstract}
${ }^{1}$ Health Economics and Decision Science, School of Health and Related Research, University of Sheffield, Sheffield S1 4DA

${ }^{2}$ Health Economics Research Group, Brunel University, Middlesex UB8 3PH

${ }^{3}$ National Collaborating Centre for Chronic Conditions, Royal College of Physicians of London, London NW1 4LE

${ }^{4}$ Royal College of Physicians of London, London NW1 4LE

${ }^{5}$ Redcar and Cleveland Primary Care Trust, Guisborough Primary Care Hospital, North Yorkshire TS14 6HZ

${ }^{6}$ Section of Musculoskeletal Disease, University of Leeds, Leeds LS7 4SA

Correspondence to: P G Conaghan p.conaghan@leeds.ac.uk
\end{abstract}

Cite this as: BMJ 2009;339:b2538 doi:10.1136/bmi.b2538

\section{ABSTRACT}

Objectives To investigate the cost effectiveness of cyclooxygenase-2 (COX 2) selective inhibitors and traditional non-steroidal anti-inflammatory drugs (NSAIDs), and the addition of proton pump inhibitors to these treatments, for people with osteoarthritis.

Design An economic evaluation using a Markov model and data from a systematic review was conducted.

Estimates of cardiovascular and gastrointestinal adverse events were based on data from three large randomised controlled trials, and observational data were used for sensitivity analyses. Efficacy benefits from treatment were estimated from a meta-analysis of trials reporting total Western Ontario and McMaster Universities (WOMAC) osteoarthritis index score. Other model inputs were obtained from the relevant literature. The model was run for a hypothetical population of people with osteoarthritis. Subgroup analyses were conducted for people at high risk of gastrointestinal or cardiovascular adverse events.

Comparators Licensed COX 2 selective inhibitors (celecoxib and etoricoxib) and traditional NSAIDs (diclofenac, ibuprofen, and naproxen) for which suitable data were available were compared. Paracetamol was also included, as was the possibility of adding a proton pump inhibitor (omeprazole) to each treatment.

Main outcome measures The main outcome measure was cost effectiveness, which was based on quality adjusted life years gained. Quality adjusted life year scores were calculated from pooled estimates of efficacy and major adverse events (that is, dyspepsia; symptomatic ulcer; complicated gastrointestinal perforation, ulcer, or bleed; myocardial infarction; stroke; and heart failure).

Results Addition of a proton pump inhibitor to both COX 2 selective inhibitors and traditional NSAIDs was highly cost effective for all patient groups considered (incremental cost effectiveness ratio less than $£ 1000$ $(€ 1175, \$ 1650)$ ). This finding was robust across a wide range of effectiveness estimates if the cheapest proton pump inhibitor was used. In our base case analysis, adding a proton pump inhibitor to a COX 2 selective inhibitor (used at the lowest licensed dose) was a cost effective option, even for patients at low risk of gastrointestinal adverse events (incremental cost effectiveness ratio approximately $£ 10000$ ). Uncertainties around relative adverse event rates meant relative cost effectiveness for individual COX 2 selective inhibitors and traditional NSAIDs was difficult to determine.

Conclusions Prescribing a proton pump inhibitor for people with osteoarthritis who are taking a traditional NSAID or COX 2 selective inhibitor is cost effective. The cost effectiveness analysis was sensitive to adverse event data and the specific choice of COX 2 selective inhibitor or NSAID agent should, therefore, take into account individual cardiovascular and gastrointestinal risks.

\section{INTRODUCTION}

Traditional non-steroidal anti-inflammatory drugs (NSAIDs) and the newer cyclo-oxygenase-2 (COX 2) selective inhibitors are commonly prescribed for people with osteoarthritis. Approximately half of the people with osteoarthritis in the United Kingdom who require medication are treated with an NSAID or a COX 2 selective inhibitor. ${ }^{1}$ COX 2 selective agents are currently prescribed much less often than traditional NSAIDs; in 2007, for example, the COX 2 selective inhibitors celecoxib and etoricoxib accounted for approximately $5.8 \%$ of total NSAID prescriptions in England and approximately $20 \%$ of the total spend. ${ }^{2}$ Although traditional NSAIDs and COX 2 selective inhibitors seem similar in terms of symptom relief in such patients, traditional NSAIDs are associated with gastrointestinal side effects. COX 2 selective agents were developed to reduce the gastrointestinal side effects of this drug class. In addition, concerns have been raised over the cardiovascular safety of both COX 2 selective inhibitors and traditional NSAIDs. ${ }^{34}$ New data indicate that co-prescribing gastroprotective agents with both traditional NSAIDs and COX 2 selective agents is beneficial. ${ }^{5-7}$ 
The latest National Institute for Health and Clinical Excellence clinical guidance for the management of osteoarthritis provides an update to previous recommendations on the use of COX 2 selective inhibitors. ${ }^{8-11}$ The previous guidance recommended that these agents should not be used routinely for patients with osteoarthritis or rheumatoid arthritis and should only be used in patients at high risk of developing serious gastrointestinal adverse events on traditional NSAIDs. In addition, the guidance stated that there was no evidence to justify the simultaneous prescription of gastroprotective agents with $\mathrm{COX} 2$ selective inhibitors. This National Institute for Health and Clinical Excellence guidance and other published economic analyses in this area preceded the latest evidence on adverse events and gastroprotection, however..$^{5912}$ In addition, drug prices have recently changed-particularly for proton pump inhibitorsand the cost effectiveness of gastroprotective agents could, therefore, also change. ${ }^{13}$

As part of the development of the latest National Institute for Health and Clinical Excellence guideline, we performed an economic evaluation of COX 2 selective inhibitors and traditional NSAIDs, and of the addition of gastroprotective agents to these treatments.

\section{METHODS}

We conducted a cost utility analysis according to the methods recommended by the National Institute for Health and Clinical Excellence. ${ }^{14}$ The primary outcome measure for the economic analysis was quality adjusted life years. A healthcare payer perspective was taken - that of the NHS in England and Wales.

\section{Comparators}

Despite the growth in the evidence base, data are still sparse regarding the adverse events associated with some NSAIDs. Amalgamating data from observational trials with data from randomised controlled trials was not feasible because of the differences in patient groups, drug doses, and adverse event definitions. To obtain evidence with the least risk of bias, we based our analysis on the largest randomised controlled trials reporting gastrointestinal and cardiovascular events with currently licensed NSAIDs: the celecoxib long-term arthritis safety study (CLASS), ${ }^{15} 16$ the therapeutic arthritis research and gastrointestinal event trial (TARGET), ${ }^{17-19}$ and the multinational etoricoxib and diclofenac arthritis longterm (MEDAL) study. ${ }^{20-22}$ Two of these trials (CLASS and the MEDAL study) included a minority of people with rheumatoid arthritis; however, the National Institute for Health and Clinical Excellence Osteoarthritis Guideline Development Group considered that the relative risks of adverse events would be similar in people with osteoarthritis and rheumatoid arthritis because there is no clear evidence of a relationship between drug induced adverse event rates and arthritis type. Table 1 gives an overview of the characteristics of the CLASS, TARGET, and the MEDAL study. These studies allow comparisons between the currently available COX 2 selective inhibitors (celecoxib and etoricoxib) and three traditional NSAIDs (diclofenac, ibuprofen, and naproxen), which together account for over $80 \%$ of NSAID prescriptions in England. "No treatment," paracetamol, and the addition of a proton pump inhibitor (omeprazole) to each NSAID were also considered. Topical NSAIDs were not included owing to data limitations.

\section{Model design}

The economic model is described in detail elsewhere. ${ }^{23}$ Here, we give an overview of the model design and parameters. The principal inputs to the model are shown in tables 2,3 , and 4 .

The model estimates the net impact of the treatment options on patient outcomes and expenditure, taking account of effects on the incidence of gastrointestinal and cardiovascular adverse events as well as improvements in the control of osteoarthritis symptoms. It is made up of a series of health states between which a theoretical cohort of patients can move. The rates of transition between these states are estimated using clinical evidence. The health states represent the most frequent and severe adverse events: dyspepsia; symptomatic ulcer; complicated gastrointestinal perforation, ulcer, or bleed; myocardial infarction; stroke; and heart failure. In addition, a patient can experience no adverse event, or death. Death rates are based on age specific mortality rates and excess mortality associated with cardiovascular and gastrointestinal adverse events. ${ }^{2425}$

The duration of treatment can be altered between three months and lifetime. The treatment duration adopted in the base case version of the model was three months. The model assumes that treatment effects do not persist after treatment is terminated

Table 1|Key characteristics of the largest randomised controlled trials reporting gastrointestinal and cardiovascular events with currently licensed NSAIDs

\begin{tabular}{|c|c|c|c|}
\hline & $\begin{array}{l}\text { The multinational etoricoxib } \\
\text { and diclofenac arthritis } \\
\text { long-term (MEDAL) study }\end{array}$ & $\begin{array}{l}\text { The therapeutic arthritis } \\
\text { research and gastrointestinal } \\
\text { event trial (TARGET) }\end{array}$ & $\begin{array}{l}\text { The celecoxib } \\
\text { long-term arthritis safety } \\
\text { study (CLASS) }\end{array}$ \\
\hline Number of participants & 34701 & 18244 & 7968 \\
\hline Mean age (years) & 63.2 & 63.4 & 60.2 \\
\hline Proportion of men (\%) & 25.8 & 23.6 & 31.2 \\
\hline Proportion of patients with osteoarthritis (\%) & 71.8 & 100 & 72.8 \\
\hline Drugs compared & Etoricoxib, diclofenac & $\begin{array}{c}\text { Lumiracoxib, ibuprofen, } \\
\text { naproxen }\end{array}$ & Celecoxib, diclofenac, ibuprofen \\
\hline
\end{tabular}


Table 2 |Model parameters-adverse event rates for patients aged 55 at low baseline risk of gastrointestinal and cardiovascular adverse events

\begin{tabular}{l}
\cline { 2 - 6 } \\
\cline { 2 - 6 }
\end{tabular}

because there is no clear evidence to the contrary. The model does, however, include the continuing impact over the patients' remaining lifetimes of adverse events experienced during the treatment period. If a patient experiences dyspepsia when being treated with a COX 2 selective inhibitor or traditional NSAID, this adverse event is treated and a proton pump inhibitor is added for the remaining duration of treatment. For patients who survive other more serious adverse events, the COX 2 selective inhibitor or traditional NSAID is stopped and replaced with paracetamol. These patients are subsequently at greater risk of having another serious gastrointestinal or cardiovascular event, based on post-event risks estimated from the literature. ${ }^{2526}$

\section{Patient populations}

Results were estimated for a cohort of patients aged 55, with baseline risks of 21 and 42 per 10000 person years for serious gastrointestinal and cardiovascular events, respectively. ${ }^{26-29} \mathrm{We}$ also ran the model with an older cohort of patients (age 65) who had a higher baseline risk (relative risks 2.96 and 1.94 for gastrointestinal and cardiovascular events, respectively). ${ }^{3031}$

\section{Adverse events}

Adverse event data were taken from the CLASS, TARGET, and the MEDAL study, and an indirect comparison was conducted. The doses of traditional NSAIDs given in these key clinical trials are generally high (but within licensed levels), whereas doses are far above licensed levels for COX 2 selective inhibitors. This disparity posed problems for our analysis because adverse events are considered to be dose related. In this paper, we present results for the lowest licensed doses that were considered to be effective for patients with osteoarthritis. The adverse event rates observed in the randomised controlled trials were adjusted by assuming that halving the dose results in a reduction in adverse events of a quarter. ${ }^{32}$ This assumption is very important but is uncertain because of the lack of data available to inform it; therefore, we incorporated uncertainty over this assumption in the probabilistic sensitivity analysis. ${ }^{33}$

The adverse event rates estimated from the randomised controlled trial data and baseline estimates of risk for the cohort of patients aged 55 are shown in table 2. The ranges given in this table were used in the probabilistic sensitivity analysis.

The effect of adding a proton pump inhibitor to traditional NSAIDs and COX 2 selective agents was estimated from a meta-analysis and trial, respectively. ${ }^{56}$ The reduction in risk was assumed to be the same for each traditional NSAID and also for each COX 2 selective inhibitor because there is not clear evidence to suggest otherwise (table 2).

\section{Costs}

The analysis included the cost to the NHS of treating side effects (table 3 ) as well as drug costs (table 4). The costs of treating gastrointestinal adverse events were

Table $3 \mid$ Model parameters-costs and utilities for all patients

\begin{tabular}{|c|c|c|c|c|c|c|}
\hline & \multicolumn{6}{|c|}{ Adverse effect } \\
\hline & Dyspepsia & $\begin{array}{l}\text { Symptomatic } \\
\text { ulcer }\end{array}$ & $\begin{array}{c}\text { Gastrointestinal } \\
\text { bleed }\end{array}$ & $\begin{array}{l}\text { Myocardial } \\
\text { infarction }\end{array}$ & Stroke & Heart failure \\
\hline \multicolumn{7}{|c|}{ Cost of adverse events ( $£$ per 3 months, 2007-8) } \\
\hline Initial 3 months & 40 & 640 & 2862 & 1437 & 2268 & 1770 \\
\hline Afterinitial 3 months & - & 19 & 19 & 134 & 435 & 134 \\
\hline \multicolumn{7}{|c|}{ Utility weights for adverse events (mean $(95 \% \mathrm{Cl})$ ) } \\
\hline Initial 3 months & $0.73(0.63$ to 0.84$)$ & $0.55(0.47$ to 0.65$)$ & $0.46(0.37$ to 0.56$)$ & 0.37 (0.28 to 0.47$)$ & $0.35(0.25$ to 0.45$)$ & $0.71(0.61$ to 0.81$)$ \\
\hline Afterinitial 3 months & 1.00 & 0.98 & 0.98 & 0.88 (0.78 to 0.98$)$ & $0.71(0.61$ to 0.80$)$ & 1.00 \\
\hline
\end{tabular}


Table $4 \mid$ Model parameters—drug costs, treatment effects, and utility gains for all patients

\begin{tabular}{|c|c|c|c|}
\hline & \multirow{2}{*}{$\begin{array}{c}\text { Drug cost } \\
\text { (£per } 3 \text { months, } \\
\text { 2007-8) }\end{array}$} & \multicolumn{2}{|c|}{ Meta-analysis results (mean $(95 \% \mathrm{CI})$ ) } \\
\hline & & $\begin{array}{l}\text { WOMAC } \\
\text { total score }\end{array}$ & $\begin{array}{l}\text { Utility weight } \\
\text { (no adverse effects) }\end{array}$ \\
\hline No treatment & - & 25.54 & 0.688 \\
\hline Paracetamol (3000 mg) & 10.64 & $23.08(21.24$ to 24.91$)$ & $0.701(0.691$ to 0.709$)$ \\
\hline Diclofenac $(100 \mathrm{mg})$ & 4.35 & \multirow{5}{*}{18.01 (16.79 to 19.22 ) } & \multirow{5}{*}{0.723 (0.718 to 0.727$)$} \\
\hline Naproxen $(750 \mathrm{mg})$ & 8.58 & & \\
\hline Ibuprofen (1200 mg) & 8.01 & & \\
\hline Etoricoxib (30 mg) & 44.97 & & \\
\hline Celecoxib (200 mg) & 64.65 & & \\
\hline Omeprazole (20 mg) & 6.43 & - & - \\
\hline
\end{tabular}

estimated on the basis of relevant Healthcare Resource Group codes and average length of stay, as given by the Department of Health reference costs. ${ }^{34}$ Costs of outpatient appointments and general practitioner consultations were also included and were based on national unit costs. ${ }^{35}$ This costing technique was similar to that used in a recent economic evaluation of gastroprotective agents. ${ }^{5}$ The costs of treating cardiovascular adverse events were estimated in a similar way, drawing on data from the Healthcare Resource Group and average length of stay reference cost data, as well as data used in the recent National Institute for Health and Clinical Excellence clinical guideline for hypertension. ${ }^{25}$ Drug costs were obtained from the British National Formulary. ${ }^{36}$ A discount rate of $3.5 \%$ was used for both costs and benefits, as recommended by the National Institute for Health and Clinical Excellence.

\section{Quality of life weights}

The Western Ontario and McMaster Universities (WOMAC) osteoarthritis index is the tool most commonly used to assess outcomes in osteoarthritis trials. ${ }^{37}$ We conducted a meta-analysis of total WOMAC scores for each treatment and used the "transfer to utility" mapping technique to estimate quality of life utility weights to reflect improvements in symptom control. ${ }^{3839}$ Our meta-analysis suggested that there was no significant difference in efficacy between COX 2 selective inhibitors and traditional NSAIDs, and there was no clear trend with regard to different doses leading to different efficacy. We therefore assumed equal utility weights for NSAIDs and COX 2 selective inhibitors for patients who do not experience adverse events (table 4). ${ }^{23}$ Both COX 2 selective inhibitors and traditional NSAIDs were superior to paracetamol, however, which was given a lower utility weight.

Utility weights for adverse events were taken from the literature. ${ }^{1225}$ On the basis of a lack of evidence for short term (three month) utility weights for myocardial infarction and heart failure, we estimated these two adverse events in relation to the short term stroke weight. ${ }^{2540} \mathrm{On}$ the basis of the guideline group's expert opinion, we assumed that heart failure events that are caused by use of NSAIDs or COX 2 selective inhibitors are likely to be short term and relatively unserious, resulting in a relatively high utility score. ${ }^{41}$

The utility weights for treatment effects and adverse events were multiplied by age specific utility scores for the general United Kingdom population taken from the Health Survey for England, which implies that the treatment effects and adverse events have an equal proportional effect on people of different ages. ${ }^{42}$

\section{Sensitivity analyses}

We used long term observational adverse event data in sensitivity analyses to test our model. The deterministic sensitivity analyses undertaken are listed in table 5 .

\section{RESULTS}

Figure 1 shows the mean estimated gain in quality adjusted life years and the costs for the 11 treatment options administered for three months compared with no treatment.

The addition of a proton pump inhibitor to any of the COX 2 selective inhibitors or other NSAIDs increases the estimated gain in quality adjusted life years at little or no additional cost (once savings from not having to treat adverse effects are taken into account). Co-prescription of a proton pump inhibitor costs less than $£ 1000(€ 1175$,

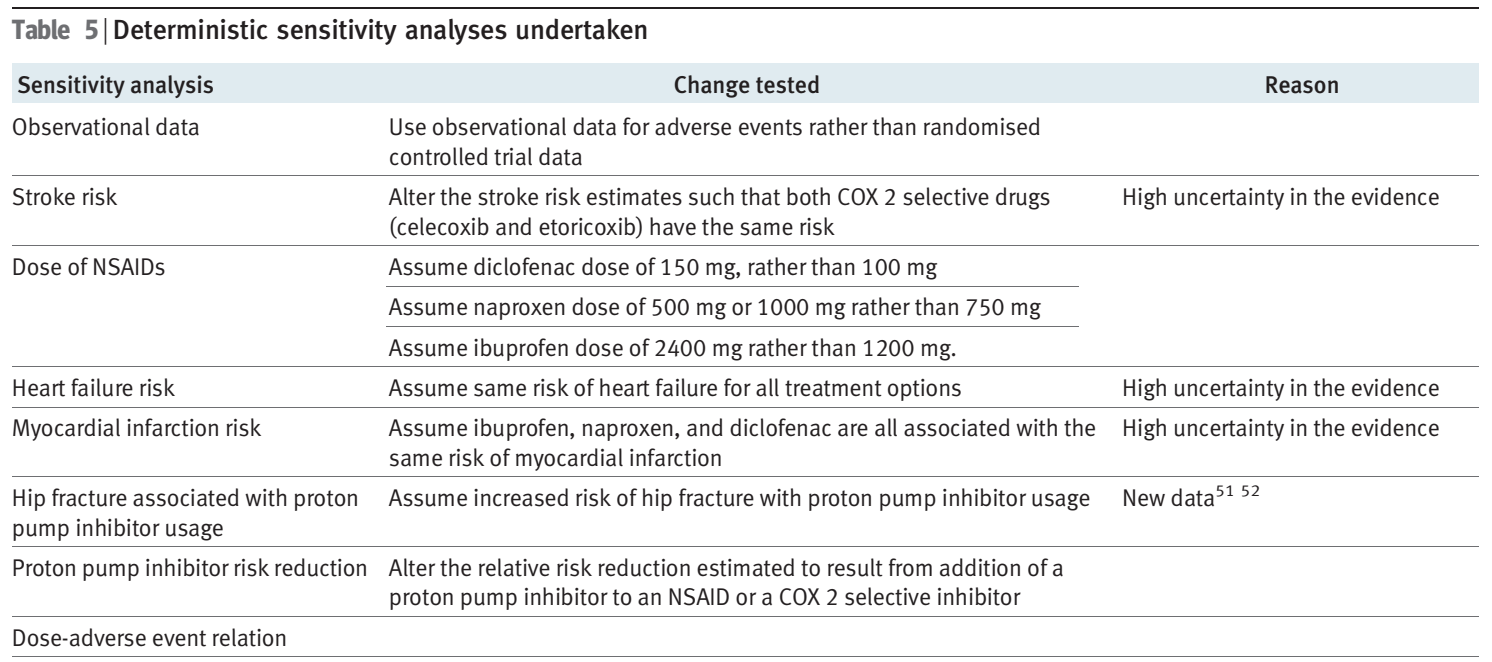



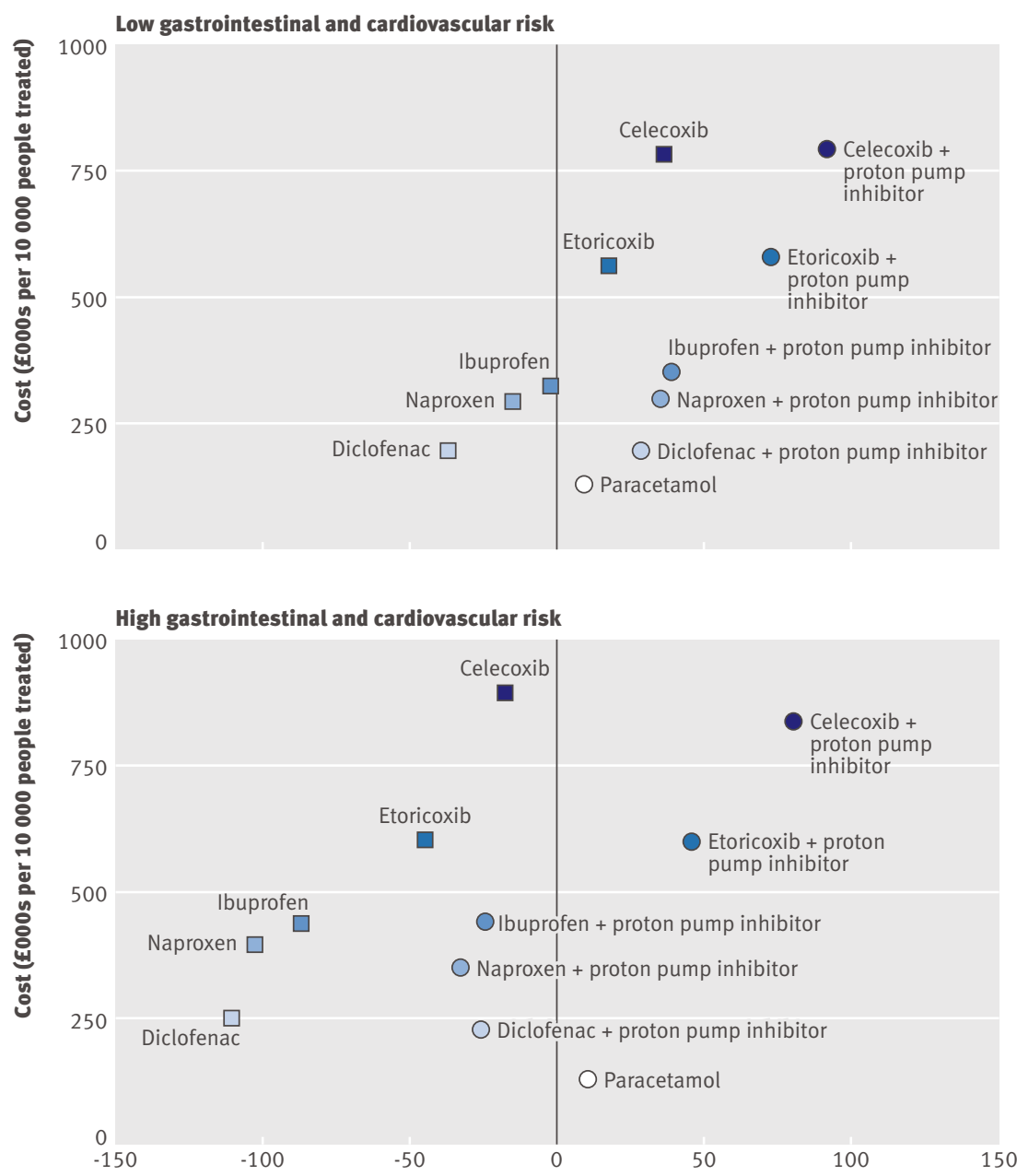

Effect (quality adjusted life years gained per 10000 people treated)

Fig 1 Expected costs and health outcomes for a cohort of people at low initial risk of gastrointestinal and cardiovascular events (equivalent to the average risk for a 55 year old) and a cohort at high risk (equivalent to the risk for an average 65 year old) treated for three months, baseline assumptions

\$1650) per additional quality adjusted life year gained, even for patients at low risk of gastrointestinal adverse events. This finding was very robust to sensitivity analysis, provided that the cheapest proton pump inhibitor (currently omeprazole) was used. In the United Kingdom, an intervention is usually classed as cost effective if the incremental cost of an additional quality adjusted life year is less than $£ 20000 .^{14}$

An incremental cost effectiveness analysis of the remaining treatment options is shown in table 6 . This analysis suggests that the most effective option, celecoxib $200 \mathrm{mg}$ with a proton pump inhibitor, can be considered cost effective, with an incremental cost effectiveness ratio estimate of around $£ 10000$ per quality adjusted life year gained for both the high risk and the low risk patient groups. There was a high degree of uncertainty around this finding, however. The cost effectiveness acceptability curves in figure 2 show that the probability of celecoxib $200 \mathrm{mg}$ with a proton pump inhibitor being the most cost effective treatment option is only $50 \%$ at a cost effectiveness threshold of
$£ 30000$ per quality adjusted life year. When we estimated adverse event rates from observational data, ${ }^{283043-45}$ celecoxib $200 \mathrm{mg}$ plus a proton pump inhibitor was of borderline cost effectiveness compared with ibuprofen $1200 \mathrm{mg}$ plus a proton pump inhibitor, with incremental cost effectiveness ratios of $£ 30400$ and $£ 21000$ per quality adjusted life year gained for 55 and 65 year old patients, respectively.

In addition, debate on the validity of cardiovascular event data from CLASS casts doubt over the superiority of celecoxib compared with etoricoxib and other treatments. According to this study, the estimated stroke rate for patients on celecoxib $200 \mathrm{mg}$ is unexpectedly low, with only 10 events per 10000 person years at risk, compared with a rate of 24 events per 10000 person years at risk for etoricoxib $30 \mathrm{mg}$ estimated from the MEDAL study. If we assume that the stroke risks estimated from the MEDAL study apply to both the COX 2 selective agents assessed in this study, etoricoxib $30 \mathrm{mg}$ plus a proton pump inhibitor becomes the most cost effective option in our model.

No reliable conclusions can be drawn from our model about the relative cost effectiveness of the traditional NSAIDs: differences were very small and highly
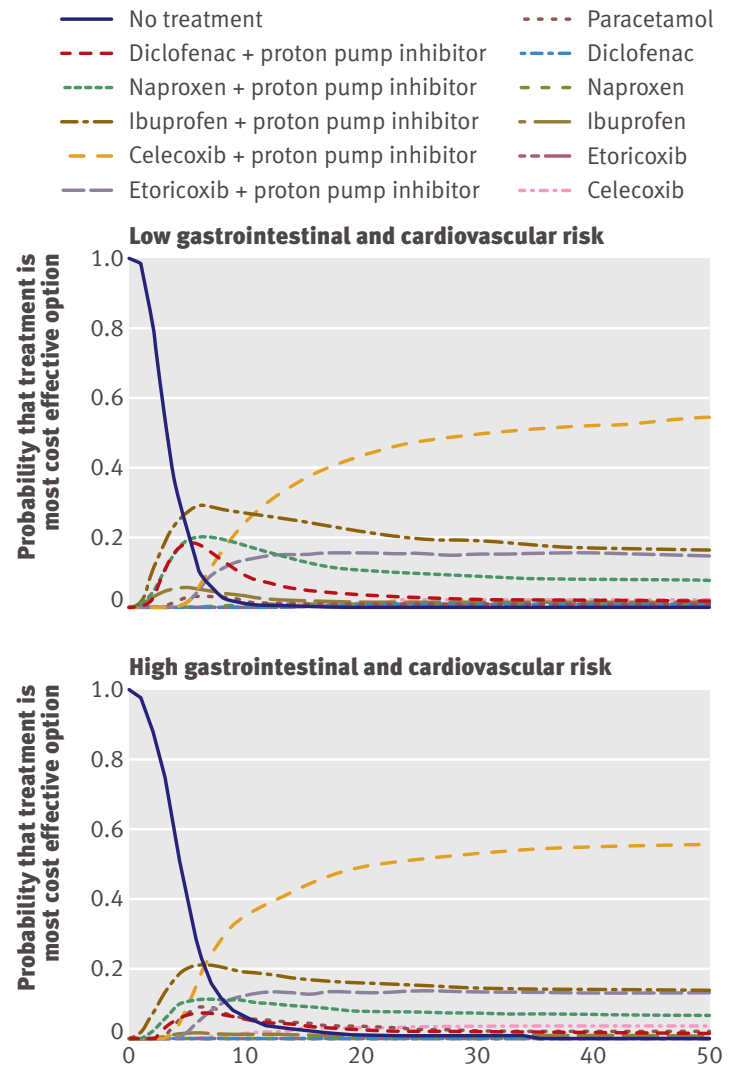

Cost effectiveness threshold (£000s per quality adjusted life year)

Fig 2 | Cost effectiveness acceptability curves for a cohort of people at low initial risk of gastrointestinal and cardiovascular events (equivalent to the average risk for a 55 year old) and a cohort at high risk (equivalent to the risk for an average 65 year old) treated for three months, baseline assumptions 
Table $6 \mid$ Cost effectiveness on the basis of three months of treatment, base case assumptions ${ }^{*}$

$$
\text { Cost per } 10000 \text { people QALYs gained per } 10000
$$

treated $(£) \quad$ people treated ICER† $(£$ per QALY)

Comparator

People at low risk of gastrointestinal and cardiovascular adverse events (age 55 with no risk factors)

\begin{tabular}{|c|c|c|c|c|}
\hline No treatment & 0 & 0.0 & - & - \\
\hline Paracetamol (3000 mg)§ & 127708 & 10.0 & - & - \\
\hline $\begin{array}{l}\text { Diclofenac }(100 \mathrm{mg}) \text { plus } \\
\text { proton pump inhibitor }\end{array}$ & 198117 & 28.4 & 6964 & No treatment \\
\hline $\begin{array}{l}\text { Naproxen }(750 \mathrm{mg}) \text { plus } \\
\text { proton pump inhibitor§ }\end{array}$ & 298657 & 35.2 & $\cdot$ & $\cdot$ \\
\hline $\begin{array}{l}\text { Ibuprofen }(1200 \mathrm{mg}) \text { plus } \\
\text { proton pump inhibitor§ }\end{array}$ & 350864 & 39.1 & - & $\cdot$ \\
\hline $\begin{array}{l}\text { Etoricoxib }(30 \mathrm{mg}) \text { plus } \\
\text { proton pump inhibitor }\end{array}$ & 580668 & 72.9 & 7472 & $\begin{array}{l}\text { Diclofenac }(100 \mathrm{mg}) \text { plus } \\
\text { proton pump inhibitor }\end{array}$ \\
\hline $\begin{array}{l}\text { Celecoxib }(200 \mathrm{mg}) \text { plus } \\
\text { proton pump inhibitor }\end{array}$ & 790859 & 92.5 & 10745 & $\begin{array}{l}\text { Etoricoxib }(30 \mathrm{mg}) \text { plus } \\
\text { proton pump inhibitor }\end{array}$ \\
\hline \multicolumn{5}{|c|}{ People at high risk of gastrointestinal and cardiovascular adverse events (age 65 or with risk factors) } \\
\hline No treatment & 0 & 0.0 & $\cdot$ & $\cdot$ \\
\hline Paracetamol (3000 mg)§ & 127965 & 10.9 & $\cdot$ & $\cdot$ \\
\hline $\begin{array}{l}\text { Diclofenac }(100 \mathrm{mg}) \text { plus } \\
\text { proton pump inhibitor }\end{array}$ & 230640 & -26.0 & - & - \\
\hline $\begin{array}{l}\text { Naproxen }(750 \mathrm{mg}) \text { plus } \\
\text { proton pump inhibitor }\end{array}$ & 352079 & -32.5 & $\cdot$ & $\cdot$ \\
\hline $\begin{array}{l}\text { Ibuprofen }(1200 \mathrm{mg}) \text { plus } \\
\text { proton pump inhibitor }\end{array}$ & 441537 & -23.6 & - & - \\
\hline $\begin{array}{l}\text { Etoricoxib }(30 \mathrm{mg}) \text { plus } \\
\text { proton pump inhibitor§ }\end{array}$ & 600650 & 46.3 & - & $\cdot$ \\
\hline $\begin{array}{l}\text { Celecoxib ( } 200 \mathrm{mg} \text { ) plus } \\
\text { proton pump inhibitor }\end{array}$ & 841035 & 80.4 & 10458 & No treatment \\
\hline
\end{tabular}

*Note that the results presented here do not exactly match those presented in Osteoarthritis: National clinical guideline for care and management in adults, Appendix $D$. This is owing to minor data input changes and also because the model was re-run with etoricoxib $30 \mathrm{mg}$ plus proton pump inhibitor included in the base case analysis.

†Incremental cost effectiveness ratio (ICER): additional cost per additional quality adjusted life year (QALY) gained comparing each non-dominated option with the next most expensive, non-dominated option.

fTreatment subject to "simple dominance": another option is less expensive and more effective.

$\S$ Treatment subject to "extended dominance": a combination of two other options is less expensive and more effective.

sensitive to the adverse event rates (figures 1 and 2). For patients at raised gastrointestinal and cardiovascular risk (equivalent to the average risk for a 65 year old), however, none of the traditional NSAIDs studied were cost effective compared with paracetamol, even when combined with a proton pump inhibitor. This is because the gain in quality adjusted life years from improved control of osteoarthritis symptoms provided by the traditional NSAIDs is outweighed by the loss from NSAID induced adverse events (figure 1).

\section{DISCUSSION}

A clear result from this analysis is it is cost effective to co-prescribe a proton pump inhibitor when either a COX 2 selective inhibitor or a traditional NSAID is given, even for patients at relatively low risk of gastrointestinal adverse events. This result is driven by recent improvements in the evidence base for proton pump inhibitors and reductions in their price. ${ }^{67}$ In the past it has not been considered usual to co-prescribe a proton pump inhibitor with a COX 2 selective inhibitor, thus this recommendation represents a change in current practice. Assuming a class effect for proton pump inhibitors, the cheapest of these agents will always be cost effective. At current prices the relative risk of gastrointestinal adverse events could be as high as 0.98 before the addition of a proton pump inhibitor becomes cost ineffective at a cost effectiveness threshold of $£ 20000$ per additional quality adjusted life year.

Another key finding of this analysis is that the coprescription of a proton pump inhibitor with a COX 2 selective inhibitor rather than a traditional NSAID might be a cost effective treatment option for younger patients without specific gastrointestinal risk factors. Previously, the use of a COX 2 selective inhibitor would have been considered only in patients at high risk of gastrointestinal adverse events. There is uncertainty over this finding, though, primarily owing to uncertainties over the adverse event data, some of which are based on low event numbers.

The relative cost effectiveness of the traditional NSAIDs depended on the adverse event data used. The sensitivity analyses showed that there is high uncertainty over which specific NSAID or COX 2 selective inhibitor is most cost effective- the results were sensitive to most of the analyses run. It is, therefore, difficult to make a firm conclusion. The same is true for the relative cost effectiveness of the two currently available COX 2 selective inhibitors. For patients at increased risk of cardiovascular or gastrointestinal events (that is, equivalent to the risk of an average 65 year old), paracetamol results in fewer 


\section{WHAT IS ALREADY KNOWN ON THIS TOPIC}

NSAIDs and COX 2 selective inhibitors are useful pharmacological treatment options for symptom relief in people with osteoarthritis

These agents are associated with significant gastrointestinal and cardiovascular adverse effects; therefore, they should be used at the lowest effective dose for the shortest possible time

\section{WHAT THIS STUDY ADDS}

This analysis does not indicate with a high degree of certainty that one NSAID or COX 2 selective inhibitor is the most cost effective

Adding a proton pump inhibitor to a traditional NSAID or to a COX 2 selective inhibitor is cost effective fact might be reflected in current prescribing patterns, given that prescriptions of COX 2 selective inhibitors form a low proportion of total NSAID prescriptions. ${ }^{2}$ Our analysis also shows that traditional NSAIDs are not likely to be more cost effective than COX 2 selective inhibitors for people with osteoarthritis who are at high risk of cardiovascular adverse events, thus both traditional NSAIDs and COX 2 selective inhibitors should be avoided in such patients. ${ }^{4}$

The limitations of this evaluation are associated with the small number of large randomised controlled trials available for inclusion, which restricted the number of agents that could be compared. Ideally, a large trial that directly compared the available NSAIDs and COX 2 selective inhibitors with and without co-prescription of a proton pump inhibitor and collected data on a range of gastrointestinal and cardiovascular adverse events would be used to populate our model. Unfortunately such data are not available.

The assumptions that we made regarding the relation between dose and efficacy also represent a limitation of our analysis. We were unable to identify a relation between dose and efficacy with the trials that we used, and thus we assumed that the utility scores associated with each treatment in the absence of adverse events were independent of dose. This presumption might not be realistic; however, we are confident that the adverse events included in the model are the main drivers behind the results and that our dose-efficacy assumption does not undermine our findings.

Additionally, the difficulties associated with amalgamating randomised controlled trial data and observational data meant that in the base case a large amount of informative observational adverse event data were not used.

Finally, we were aware of new data suggesting that long term proton pump inhibitor use may be linked to hip fractures ${ }^{5051}$; thus we tested the impact of this possibility in a sensitivity analysis. We found that hip fractures were so rare that they made no difference to the results of the economic analysis.

\section{CONCLUSIONS}

Although uncertainty around some of the results is high, our findings clearly indicate that when prescribing an NSAID or a COX 2 selective inhibitor for patients with osteoarthritis, it is cost effective to add a proton pump inhibitor. Co-prescription of a proton pump inhibitor with a COX 2 inhibitor is a new message for clinicians, but this evaluation illustrates that the number of adverse events avoided is very good value for money.

We gratefully acknowledge the advice and input of the following members of the Osteoarthritis Guideline Development Group and experts who advised the group regarding this economic evaluation: Fraser Birrell, Michael Burke, Jo Cumming, Paul Dieppe, Mike Doherty, Krysia Dziedzic, Roger Francis, Christine Kell, Alex MacGregor, Carolyn Naisby, Susan Oliver, Alison Richards, Martin Underwood, Garry Barton, and Bernard Higgins.

Funding: The National Institute for Health and Clinical Excellence commissioned and funded this analysis. 
Competing interests: All authors were members of the National Institute for Health and Clinical Excellence Osteoarthritis Guideline Development Group (PGC chaired the group, JD was the clinical adviser, RLG was project manager, NL was the health economist, JL was the National Institute for Health and Clinical Excellence technical adviser, and RO was the research fellow). During the guidelines process, PGC received travel grants to educational meetings and honoraria for joint injection tutorials from Merck, Sharp \& Dohme, he has also been adviser to Novartis and Bristol Myers Squibb on imaging studies in rheumatoid arthritis. JD has received travel grants from Pfizer, Wyeth, Novartis, and Napp, and honoraria for tutorials from Pfizer and Novartis. He has also been on advisory boards for pharmaceutical companies including GlaxoSmithKline, Wyeth, and Novartis. After completing the guideline analysis but before its publication, NL joined Roche Products and has since moved to the University of Sheffield. RLG, JL, and RO have no competing interests.

Ethical approval: Ethical approval was not required for this research.

1 Prescription Pricing Authority. Prescription Pricing Authority Newsletter. March

2005, pg 2-4. http://www.ppa.org.uk/pdfs/imPACT/imPACT\% 20March\%202005.pdf (accessed 29 April 2008).

2 National Health Service National Prescribing Centre. Cardiovascular and Gastrointestinal safety of NSAIDs. MeReC Extra Issue No. 30, November 2007. http://www.npc.co.uk/MeReC_Extra/2008/ no30_2007.html\#CVR(accessed 29 April 2008).

3 Medicines and Healthcare products Regulatory Agency. Cardiovascular safety of COX-2 inhibitors and non-selective NSAIDs. 15 April

2008. http://www.mhra.gov.uk/Safetyinformation/ Generalsafetyinformationandadvice/Productspecificinformationandadvice/CardiovascularsafetyofCOX 2inhibitorsandnon-selectiveNSAIDs/index.htm (accessed 29 April 2008).

4 Mayor S. US heart group says COX 2 inhibitors should be last choice for pain relief in patients at risk. BMJ 2007;334:441.

5 Brown TJ, Hooper L, Elliott RA, Payne K, Webb R, Roberts C, et al. A comparison of the cost-effectiveness of five strategies for the prevention of non-steroidal anti-inflammatory drug-induced gastrointestinal toxicity: a systematic review with economic modelling. Health Technol Assess 2006:10:iii-iv,xi-xiii,1-183.

6 Scheiman JM, Yeomans ND, Talley NJ, Vakil N, Chan FK, Tulassay Z, et al. Prevention of ulcers by esomeprazole in at-risk patients using non-selective NSAIDs and COX 2 inhibitors. Am J Gastroenterol 2006;101:701-10

7 Chan FK, Wong VW, Suen BY, Wu JC, Ching JY, Hung LC, et al. Combination of a cyclo-oxygenase-2 inhibitor and a proton-pump inhibitor for prevention of recurrent ulcer bleeding in patients at ven high risk: a double-blind, randomised trial. Lancet 2007;369:1621-6.

8 National Institute for Health and Clinical Excellence. Guidance on the use of Cyclo-oxygenase (Cox) II selective inhibitors, celecoxib, rofecoxib, meloxicam and etodolac for osteoarthritis and rheumatoid arthritis. Technology Appraisal Guidance no 27, July

2001. http://www.nice.org.uk/nicemedia/pdf/coxifullguidance.pdf (accessed 29 April 2008)

9 Chen Y-F, Jobanputra P, Barton P, Bryan S, Fry-Smith A, Harris G, et al. Cyclooxygenase-2 selective non-steroidal anti-inflammatory drugs (etodolac, meloxicam, celecoxib, rofecoxib, etoricoxib, valdecoxib and lumiracoxib) for osteoarthritis and rheumatoid arthritis: a systematic review and economic evaluation. Health Technol Assess 2008;12:1-278, iii.

10 National Collaborating Centre for Chronic Conditions (NCCCC) on behalf of the National Institute for Health and Clinical Excellence. Osteoarthritis: National clinical guideline for care and management in adults. London: Royal College of Physicians, February 2008, http://www.nice.org.uk/nicemedia/pdf/CG059FullGuideline. pdf(accessed 29 April 2008).

11 Conaghan P, Dickson J, Grant R on behalf of the Guideline Development Group. Care and management of osteoarthritis in adults: summary of NICE guidance. BMJ 2008;336:502-3.

12 Maetzel A, Krahn M, Naglie G. The cost-effectiveness of celecoxib and rofecoxib inpatients with osteoarthritis or rheumatoid arthritis. Technology Report no 23. Ottawa: Canadian Coordinating Office for Health Technology Assessment, 2001.

13 National Health Service Business Services Authority Prescription Pricing Division. National Health Service England and Wales Electronic Drug Tariff. February

2008. http://www.ppa.org.uk/edt/February_2008/mindex.htm (accessed 19 February 2008).

14 National Institute for Health and Clinical Excellence. The Guidelines Manual. April

2007. http://www.nice.org.uk/niceMedia/pdf/ GuidelinesManualAllChapters.pdf (accessed 29 April 2008).
15 Silverstein FE, Faich G. Gastrointestinal toxicity with celecoxib vs nonsteroidal anti-inflammatory drugs for osteoarthritis and rheumatoid arthritis: the CLASS study: a randomized controlled trial. JAMA 2000;284:1247-55.

16 United States Food and Drug Administration. Medical Officer Review: Celebrex (celecoxib). NDA 20-998/S-009. 20 September 2000. http://www.fda.gov/ohrms/dockets/AC/01/briefing/ 3677b1_03_med.pdf (accessed 19 May 2008).

17 Farkouh ME, Kirschner H. Comparison of lumiracoxib with naproxen and ibuprofen in the Therapeutic Arthritis Research and Gastrointestinal Event Trial (TARGET), cardiovascular outcomes: randomised controlled trial. Lancet 2004;364:675-84.

18 Schnitzer TJ, Burmester GR, Mysler E. Comparison of lumiracoxib with naproxen and ibuprofen in the Therapeutic Arthritis Research and Gastrointestinal Event Trial (TARGET), reduction in ulcer complications: randomised controlled trial. Lancet 2004:364:665-74.

19 Novartis. Prexige (Frexocel, Hirza, Stellige) (lumiracoxib, COX189) Drug Regulatory Affairs, Clinical Development \& Medical Affairs, Clinical Epidemiology \& Safety. 15 December 2006. http://www.mhra.gov.uk/home/idcplg? IdcService=GET_FILE\&dDocName=con2022709\&RevisionSelection Method=Latest (accessed 25 June 2009).

20 Laine L, Curtis SP, Cryer B, Kaur A, Cannon C. Assessment of upper gastrointestinal safety of etoricoxib and diclofenac in patients with osteoarthritis and rheumatoid arthritis in the Multinational Etoricoxib and Diclofenac Arthritis Long-term (MEDAL) programme: a randomised comparison. Lancet 2007;369:465-73.

21 Laine L, Curtis S, Bombardier C, Weinblatt ME, Kaur A, Cannon CP, et al. Clinical Outcomes following long term treatment with etoricoxib versus diclofenac in 34,701 patients with osteoarthritis or rheumatoid arthritis: primary results of the multinational etoricoxib and diclofenac arthritis Long-term (MEDAL) program. Presentation L37. Program and Abstracts of the American College of Rheumatology 2006 Annual Meeting; 11-15 November 2006; Washington, DC

22 Medicines and Healthcare products Regulatory Agency (MHRA). Pharmacovigilance Working Party (PhWWP) Assessment Report. Etoricoxib, Diclofenac. London: MHRA,September 2006.

23 National Collaborating Centre for Chronic Conditions (NCCCC) on behalf of the National Institute for Health and Clinical Excellence. Osteoarthritis: National clinical guideline for care and management in adults, Appendix D: Details of the NSAID/COX-2 inhibitor health economic model. London: Royal College of Physicians, February 2008

24 Maetzel A, Ferraz MB, Bombardier C. The cost effectiveness of misoprostol in preventing serious gastrointestional events associated with the use of nonsteroidal antiinflammatory drugs. Arthritis Rheum 1998;41:16-25.

25 National Institute for Health and Clinical Excellence. Hypertension. Management of hypertension in adults in primary care: partial update. London: NICE, 2006.

26 Rodriguez LAG, Hernandez-Diaz S. Relative risk of upper gastrointestinal complications among users of acetaminophen and nonsteroidal anti-inflammatory drugs. Epidemiology 2001;12:570-6

27 Kearney PM, Baigent C, Godwin I. Halls H, Emberson IR, Patrono C. Do selective cyclo-oxygenase inhibitors and traditional non-steroidal anti-inflammatory drugs increase the risk of atherothrombosis? Meta-analysis of randomised trials. BMJ 2006;332:1302-05

28 Mamdani M, Juurlink DN, Lee DS, Rochon PA, Kopp A, Naglie G. Cyclooxygenase-2 inhibitors versus nonselective non-steroidal antiinflammatory drugs and congestive heart failure outcomes in elderly patients: a population-based cohort study. Lancet 363:1751-6.

29 Laine L. GI risk and risk factors of NSAIDs. / Cardiovasc Pharmacol 2006;47(Suppl 1):60-66S.

30 Hippisley-Cox J, Coupland C, Logan R. Risk of adverse gastrointestinal outcomes in patients taking cyclo-oxygenase-2 inhibitors or conventional non-steroidal anti-inflammatory drugs: population based nested case-control analysis. BM 2005:331:1310-6.

31 Hippisley-Cox J, Coupland C, Vinogradova Y, Robson J, May M, Brindle P. Derivation and validation of QRISK, a new cardiovascular disease risk score for the United Kingdom: prospective open cohort study. BMJ 2007;335:136.

32 Bloor K, Maynard A. Is there scope for improving the cost-effective prescribing of nonsteroidal anti-inflammatory drugs? Pharmacoeconomics 1996;9:484-96.

33 Briggs A. Handling uncertainty in economic evaluation. $B M$ J 1999;319:120.

34 Department of Health. NHS reference costs 2005-06. London: DH, 2006.

35 Curtis L, Netten A. Unit Costs of Health \& Health Social Care. Kent: University of Kent, 2006

36 British National Formulary. 53rd ed. London: BMJ Publishing and 
Royal Pharmaceutical Society of Great Britain, 2007.

37 Bellamy NW, Buchanan W, Goldsmith C, Campbell J, Stitt L. Validation study of WOMAC: a health status instrument for measuring clinically important patient relevant outcomes to antirheumatic drug therapy in patients with osteoarthritis of the hip or knee. J Rheumatol 1988;15:1833-40.

38 Segal L, Day S, Chapman A, Osborne R. Priority setting in osteoarthritis. Melbourne: Monash University, 2003.

39 Barton GR, Sach T, Jenkinson C, Avery A, Doherty M, Muir KR. Do estimates of cost-utility based on the EQ-5D differ from those based on the mapping of utility scores? Health Qual Life Outcomes 2008;6:51.

40 Pickard A, Johnson J, Feeny D. EQ-5D. Responsiveness of generic health-related quality of life measures in stroke. Qual Life Res 2005;14:207-19.

41 Center on the Evaluation of Value and Risk in Health. Preference weights 1998-2001. Institute for Clinical Research and Health Policy Studies, Tufts-New England Medical Center, Boston, MA. http:// www.tufts-nemc.org/cearegistry/ (Accessed 29 April 2008).

42 Department of Health. Health Survey for England. London: DH, 1998

43 Andersohn F, Schade R, Suissa S, Garbe E. Cyclooxygenase-2 selective nonsteroidal anti-inflammatory drugs and the risk of ischemic stroke: a nested case-control study. Stroke 2006;37:1725-30

44 Medicines and Healthcare products Regulatory Agency. Pharmacovigilance Working Party (PhVWP) Assessment Report Diclofenac, Ibuprofen, Naproxen. London: MHRA, 2006.
45 Hernandez-Diaz S, Varas-Lorenzo C, Garcia Rodriguez LA. Nonsteroidal antiinflammatory drugs and the risk of acute myocardia infarction. Basic Clin Pharmacol Toxicol 2006;98:266-74.

46 Dieppe P, Cushnaghan J, Jasani MK, McCrae F, Watt I. A two-year, placebo-controlled trial of non-steroidal anti-inflammatory therapy in osteoarthritis of the knee joint. Br J Rheumatol 1993;32:595-600.

47 Scott DL, Berry H, Capell H, Coppock J, Daymond T, Doyle DV, et al. The long-term effects of non-steroidal anti-inflammatory drugs in osteoarthritis of the knee: a randomized placebo-controlled trial. Rheumatology 2000;39:1095-101.

48 Williams HJ, Ward JR, Egger MJ, Neuner R, Brooks RH, Clegg DO, et al. Comparison of naproxen and acetaminophen in a two-year study of treatment of osteoarthritis of the knee. Arthritis Rheum 1993;36:1196-206

49 Spiegel BM, Targownik L, Dulai GS, Gralnek IM. The costeffectiveness of cyclooxygenase-2 selective inhibitors in the management of chronic arthritis. Ann Intern Med 2003;138:795-806

50 Vestergaard P, Rejnmark L, Mosekilde L. Proton pump inhibitors, histamine $\mathrm{H} 2$ receptor antagonists, and other antacid medications and the risk of fracture. Calcif Tissue Int 2006;79:76-83.

51 Yang YX, Lewis JD, Epstein S, Metz D. Long-term proton pump inhibitor therapy and risk of hip fracture. JAMA 2006;296:2947-53.

Accepted: 10 February 2009 